ANUARIO DE ESTUdios MEDIEVALES

48/1, enero-junio de 2018, pp. 213-242

ISSN 0066-5061

https://doi.org/10.3989/aem.2018.48.1.07

\title{
INTEGRACIÓN ECONÓMICA, COMPETENCIA Y JERARQUIZACIÓN DE LOS PUERTOS ATLÁNTICOS DEL NORTE DE ESPAÑA (SIGLOS XIII-XV)*
}

\author{
ECONOMIC INTEGRATION, COMPETITION AND HIERARCHIZATION OF \\ THE ATLANTIC PORTS OF NORTHERN SPAIN (13 ${ }^{\text {th }}-15^{\text {th }}$ CENTURIES)
}

\author{
JESÚS ÁNGEL SOLÓRZANO TELECHEA \\ Universidad de Cantabria \\ http://orcid.org/0000-0002-0640-8600
}

\begin{abstract}
Resumen: El objetivo de este artículo es analizar las relaciones y la jerarquía de las villas portuarias del Atlántico norte de España entre los siglos XIII y XV. Los puertos del norte peninsular operaban en un nivel intermedio, regional e internacional, de la estructura comercial europea. Las cincuenta villas portuarias de la costa cantábrica desempeñaron un papel vital en la conectividad urbana del tráfico marítimo internacional entre el Mediterráneo y el Atlántico. El fenómeno portuario del Cantábrico, a pesar de su falta de homogeneidad, fue un éxito porque se basó en algunos factores claves, como las características geográficas, las infraestructuras portuarias, el apoyo regio y unas sociedades muy dinámicas; además, la política y la gobernanza adoptaron unas características comunes y distintas en estas villas periféricas para responder a las necesidades y condiciones locales, muy influidas por su carácter de frontera marítima de la Corona de Castilla.
\end{abstract}

Palabras clave: Edad Media; Corona de Castilla; España atlántica; costa cantábrica; comercio; conectividad; relaciones portuarias; jerarquía urbana.

Abstract: The aim of this article is to analyze the relationships and the hierarchy of the port-towns of Atlantic Northern Spain between the $13^{\text {th }}$ and $15^{\text {th }}$ centuries. The port-towns operated in an intermediate level, both regional and international, of the European trade structure. The half a hundred port-towns on the Cantabrian coast played a vital role in the urban connectivity of the international maritime traffic between the Mediterranean and the Atlantic. This phenomenon, despite lacking an homogeneity, was a success because it was based on some key factors, such as geographical features, port infrastructures, royal support and very dynamic societies. Besides, politics and governance adopted common and distinct characteristics in these peripheral towns to respond to local needs and conditions, very influenced by their character as a maritime border of the kingdom of Castile.

Keywords: Middle Ages; Crown of Castile; Atlantic Spain; Cantabrian coast; commerce; connectivity; port relations; urban hierarchy.

\section{SUMARIO}

1. Introducción.- 2.Ventajas y retos de la ubicación geográfica de los puertos del Cantábrico. 3. La afirmación del poder regio en la fundación de los puertos del Cantábrico.4. Instalaciones e infraestructuras portuarias.- 5. La intervención y el control portuario del espacio costero.- 6. El papel de los puertos del Cantábrico en la maritimización del norte peninsular.- 7. Conclusiones.- 8. Bibliografía citada.

\footnotetext{
* Este trabajo se inscribe en las tareas de investigación de los proyectos: "Política, instituciones y gobernanza de las villas y ciudades portuarias de la Europa Atlántica en la Baja Edad Media: análisis comparativo transnacional” (HAR2017-83801-P); de la Red de Excelencia La Gobernanza de los puertos atlánticos, siglos XIV-XXI (HAR2016-81812-REDT) y "Social and Political Order of the Communal Towns in the European Peripheries from the $12^{\text {th }}$ to $16^{\text {th }}$ Century" $(340880$, ARMONIA, HS3).

Cómo citar este artículo: Solórzano Telechea, Jesús Ángel (2018), Integración económica, competencia y jerarquización de los puertos atlánticos del Norte de España (siglos XIII-XV), "Anuario de Estudios Medievales" 48/1, pp. 213-242. https://doi.org/10.3989/aem.2018.48.1.05

Copyright: (C) 2018 CSIC. Este es un artículo de acceso abierto distribuido bajo los términos de la licencia de uso y distribución Creative Commons Reconocimiento 4.0 Internacional (CC BY 4.0).
} 


\section{INTRODUCCIÓN}

La historia portuaria se ha convertido, en los últimos años, en un campo de investigación preocupado por la génesis, el desarrollo y la transformación de las conexiones interurbanas, puesto que las ciudades portuarias están ubicadas en el corazón de las relaciones de comunicación, por lo que han de ser estudiadas si queremos conocer mejor el complicado juego entre puertos, mercados y gentes. El objetivo del presente trabajo es llevar a cabo "un análisis histórico integrado y dinámico" de las relaciones y la jerarquización de las villas portuarias del Cantábrico en la Edad Media en el marco del presente dossier, coordinado por nuestra colega la profesora María Asenjo González ${ }^{1}$.

La historiografía "tradicional" sobre relaciones interurbanas se ha centrado especialmente en el estudio de las redes regionales y en analizar la manera en que los centros urbanos se han integrado en una jerarquía urbana regional dada y su papel en los sistemas urbanos ${ }^{2}$. Wim Blockmans añadió, hace algunos años, que una red urbana conllevaba el desarrollo de relaciones multilaterales por medio de "flujos" de gentes, ideas, innovaciones y, por supuesto, de productos, y concluía que antes que estudiar las jerarquías urbanas, había que determinar el tipo de flujos existente entre los distintos lugares de la red $^{3}$. Otros expertos en redes han sido mucho más restrictivos en el uso del concepto, como es el caso de Mike Burkhardt, para quien solo se puede hablar de una red cuando se dan una serie de situaciones muy concretas, como la libre participación, la existencia de unas metas comunes para cuya consecución se cuenta con la ayuda de la red, la transferencia de recursos en la red, una jerarquización débil en la que cada actor de la red tiene al menos lazos con otros dos participantes de la red y hay una institución formal ${ }^{4}$. No obstante, en los últimos años, se observa un incremento del número de análisis sobre las interacciones entre diversos elementos, como los individuos, los grupos, las políticas, las mercancías e, incluso, de términos y conceptos viajeros (travelling concepts), documentados por los testimonios escritos o las evidencias arqueológicas, que pueden ayudarnos a reconstruir los modelos de relaciones interurbanas ${ }^{5}$. Varios han sido los estudios que han otorgado una gran importancia a la conectividad entre los núcleos urbanos y, en concreto, a las infraes-

\footnotetext{
${ }^{1}$ Solórzano, Arízaga 2002; Arízaga, Solórzano 2005.

${ }^{2}$ Laughton, Jones, Dyer 2001, pp. 331-357.

${ }^{3}$ Blockmans 1992; 2013, pp. 243-248.

${ }^{4}$ Burkhardt 2014, p. 15; Christ 2014.

${ }^{5}$ Preiser-Kapeller 2015, pp. 1-24. Igual Luis 2013, p. 59. Sobre los conceptos viajeros: Bal 2002.
} 
tructuras, pero hay que tener en cuenta que las infraestructuras son posteriores a la formación de las relaciones interurbanas, de hecho muchas de ellas, como las infraestructuras portuarias, no se generalizaron en Europa hasta el siglo $\mathrm{XV}$. Así, los principales conectores entre los centros urbanos fueron sus gentes, por lo que es necesario analizar el factor humano, en profundidad, para conocer los mecanismos de funcionamiento de las relaciones interurbanas ${ }^{6}$.

La historiografía urbana ha dado prioridad al estudio de los grandes puertos sobre los pequeños; sin embargo, los trabajos sobre el comercio marítimo, la navegación y las sociedades portuarias han demostrado el importante papel desempeñado por los pequeños y medianos puertos en las conexiones y permiten corregir la miopía de los estudios macroeconómicos ${ }^{7}$. En este sentido, los puertos del Cantábrico constituyeron un subsistema del sistema urbano de la Corona de Castilla y de sus relaciones con el Mediterráneo y el Atlántico, que se asentó sobre una serie de factores, como las condiciones geográficas, la dinámica política-administrativa, las infraestructuras y las relaciones económicas y, en especial, comerciales, que van a ser objeto del presente trabajo ${ }^{8}$.

La historiografía de los puertos atlánticos de la España medieval ha estado dominada por la historia urbana y marítima, con énfasis en las actividades mercantiles hasta entrado el siglo XXI. La historia urbana del Cantábrico se distingue por su análisis de villas portuarias de manera individual o bien de los centros urbanos en el marco regional actual; solo Jean Gautier-Dalché y Juan Ignacio Ruiz de la Peña se aventuraron, hace ya algunos años, fuera de este paradigma para considerar el mundo urbano de la España atlántica en su conjunto9. El resto de estudios han centrado su atención en cinco temas principales: el urbanismo, la concesión de cartas y privilegios, las relaciones comerciales, los conflictos territoriales y la conflictividad socio-política. Claramente, a pesar de todo lo que se ha hecho en los últimos años desde los grupos de investigación de las universidades del norte peninsular, algunas dimensiones importantes de la historia urbana permanecen inexploradas, especialmente la aparición de las relaciones interurbanas en el Cantábrico y la cuestión aun más amplia de la relación entre esta región y el resto de Europa occidental ${ }^{10}$. Sin duda, una clave de esta laguna de estudios se debe a la falta de documentación cuantitativa que nos informe de los flujos portuarios del Cantábrico, pues sólo se cuenta con documentación concejil, regia, judicial,

\footnotetext{
${ }^{6}$ Scott, Scribner 1996, pp. 113-143.

${ }^{7}$ Un balance de la historiografía portuaria atlántica medievales en Andrade, et al. 2016.

${ }^{8}$ Ruiz de la Peña 1981; García Oro 1987; Solórzano, Arízaga 2002; Solórzano 2009b.

${ }^{9}$ Gautier-Dalché 1979; Ruiz de la Peña 1989, 1997.

${ }^{10}$ Sobre esta cuestión, véanse los trabajos Solórzano 2007-2008, 2009a, 2009b, 2013, 2015; Andrade, et al. 2016.
} 
mercedes y privilegios, con la excepción de las cuentas de los "diezmos de la mar" o las averías navales del puerto de Bilbao entre 1481 y $1501^{11}$. Mucha más información proporcionan las fuentes de los puertos europeos, como es el caso de los Port books y Brokage Books de Southampton, los Gascon Rolls, Calender of Fine Rolls, Patent Rolls y Close Rolls, Exchequer rolls of Scotland, los registros de sentencias civiles y el gran fondo documental de la Nación de España en Brujas, entre otros muchos, cuya relación exhaustiva excedería con mucho la extensión del presente artículo.

\section{VENTAJAS Y RETOS DE LA UBICACIÓN GEOGRÁFICA DE LOS PUERTOS DEL CANTÁBRICO}

En los albores del siglo XII, la costa cantábrica era un territorio absolutamente rural, dominado por los señoríos laicos y eclesiásticos, y muy aislado debido a su orografía ${ }^{12}$. Sólo unos pocos puertos, de muy reducido tamaño, habían surgido en los siglos altomedievales, como Gijón, Santander, Castro Urdiales, Zarauz, Guetaria, Irún... ${ }^{13}$. La Historia Compostelana relata que

los campesinos del litoral del Océano abandonaban la costa desde la mitad de la primavera hasta mediado el otoño o se escondían en cuevas con toda su familia para huir de las razzias musulmanas de la costa ${ }^{14}$.

La guía del peregrino a Compostela describía Galicia como una tierra scasa en ciudades y villas y el obispo de Oporto, Hugo, a su paso por la costa cantábrica, no menciona ningún puerto y refiere el carácter inhóspito y las dificultades de los caminos debido al mar y los acantilados ${ }^{15}$. Sin embargo, a principios del siglo XIV, habían surgido cincuenta puertos a lo largo de la llamada Costeira do gran mar d'Espanna, desde Irún a la Bayona gallega, una larga costa de $1300 \mathrm{~km}$.

Las condiciones geográficas y climáticas del litoral cantábrico son, en general, poco favorables para el establecimiento portuario, según el modelo que Braudel señaló para el Mediterráneo, ya que es un mar abierto al Atlántico, con

\footnotetext{
${ }^{11}$ Ferreira Priegue1988; González Arce 2015; Vítores Casado 2015.

${ }^{12}$ Blot 2003; Arízaga, Solórzano 2005; Bengoetxea, Quirós 2006, pp. 147-165; Blair 2000, pp. 245-270.

${ }^{13}$ Solano 2016; García de Cortázar 1982, pp. 89-111.

${ }^{14}$ Falque 1994, p. 338.

${ }^{15}$ Guía del peregrino medieval 1989, p. 38.
} 
una geografía abrupta y un clima variable ${ }^{16}$. No obstante, la costa cantábrica está dotada de los requisitos geográficos necesarios para el desarrollo de un puerto, como son la disponibilidad de zonas arenosas para la carga y descarga de los barcos, collados que protegen los puertos del azote tanto de los enemigos que puedan llegar por mar, como de los vientos y borrascas que entran por el oeste, $\mathrm{y}$, además, toda la costa es rica en agua dulce. El litoral del norte peninsular tampoco es un todo homogéneo, ya que la costa gallega presenta numerosas rías profundas, mientras que la orla cantábrica es rectilínea con pocos entrantes que puedan acoger a las poblaciones, siendo la bahía de Santander una excepción. Hay que sumar también que los puertos de la costa presentan unas graves carencias de comunicación con el interior de la Meseta debido al Macizo Galaico y la cordillera Cantábrica que llega hasta las estribaciones de los Pirineos. Por lo tanto, las poblaciones del litoral vieron en el mar su única salida posible. La dificultad de conexión con el interior, hizo del mar una vía excepcional -y a veces única- de unión entre los puertos del Cantábrico y la proximidad a este medio fue un factor fundamental para la elección de su asentamiento. Así nos consta documentado en la petición del concejo de Deba de 1343 para reasentar cerca del mar la villa que había sido aforada en 1294, debido a que si se situaban en la ribera tendrían acceso a los cereales y otros mantenimientos ${ }^{17}$. Con todo, en otros casos, el desarrollo de algunas villas quedó truncado a causa de su ubicación geográfica junto al mar. Es el caso del puerto de Plencia, que se creó en la desembocadura del río Butrón, junto al mar, y estuvo muy determinado por las mareas, lo que le impidió disfrutar de un desarrollo comercial y pesquero mayor. Los peligros de la mar también ayudaron a consolidar la solidaridad entre las gentes de estos puertos. La cofradía de San Andrés de Castro Urdiales tenía recogido en sus ordenanzas la obligación de ocuparse de las personas enfermas que llegaran a la villa y murieran en ella, debiendo encargarse de la devolución del cuerpo cuando se tratara de un vecino de los cercanos puertos de Santander, Laredo, Portugalete, Plencia y Bermeo:

que por cuanto en esta villa suele haber y hay personas enfermas que vienen por la mar y por la tierra de estos reynos y de fuera de ellos que son vecinos cercanos a esta villa, en especial, Laredo, Santander, Portugalete, Plencia y Bermeo y mueren en esta dicha villa (...) que los dichos mayordomos del dicho cabildo procuren gente o barco en que llevar los dichos cuerpos o los lleven dos clérigos o cruz de la iglesia parroquial con cuatro hachas de cera entreguen los dichos cuerpos en las dichas partes ${ }^{18}$.

\footnotetext{
${ }^{16}$ Braudel 2001; Coulon, Picard, Valérian 2007.

${ }^{17}$ Herrero, Barrena 2006, p. 15.

${ }^{18}$ Garay, Ojeda 2003, p. 135.
} 
En suma, la geografía de la costa cantábrica no era propicia para la fundación portuaria, pero la principal ventaja con la que contaron las villas portuarias era su ubicación estratégica en medio de la ruta que unía dos grandes complejos marítimos, el Mediterráneo y el Atlántico, lo que las convertía en obligado lugar de paso para las embarcaciones del norte y el sur, además de salida natural de las mercancías y las personas del interior peninsular.

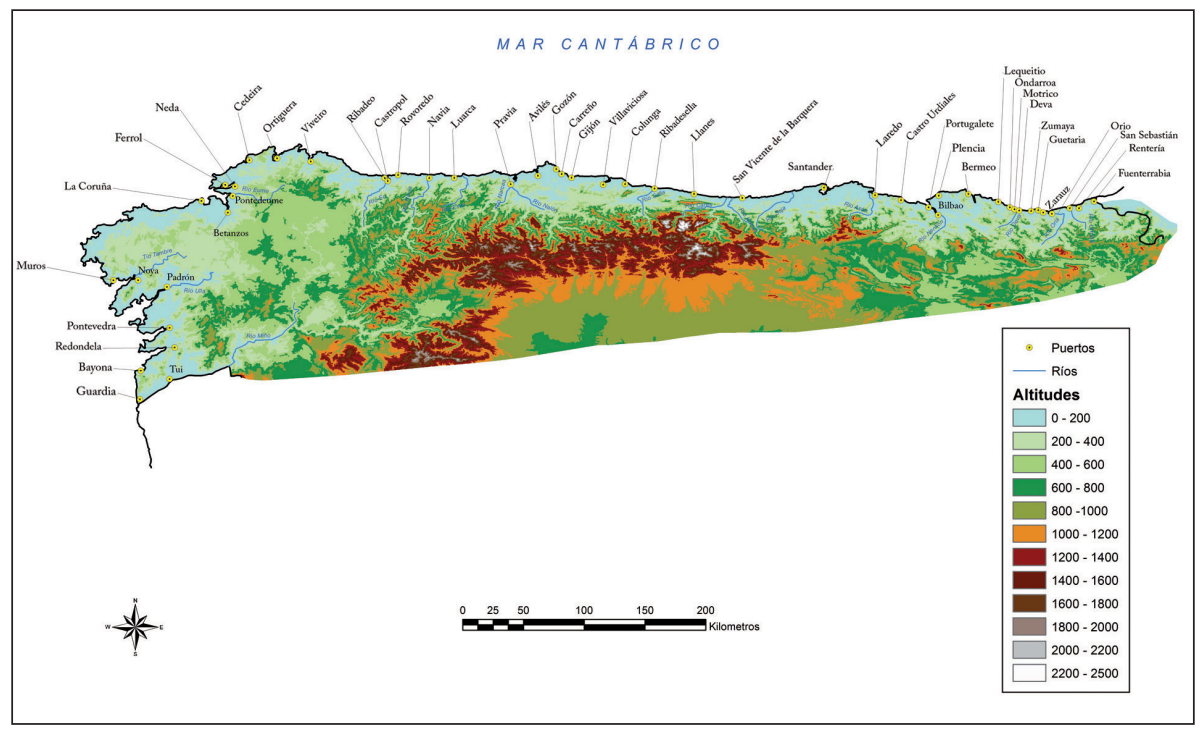

Fig. 1. Los puertos del Cantábrico a finales de la Edad Media. () Solórzano y Cayón.

\section{LA AFIRMACIÓN DEL PODER REGIO EN LA FUNDACIÓN DE LOS PUERTOS DEL CANTÁBRICO}

La fundación de puertos en el Cantábrico se inició en el siglo XII como un proyecto específico de los reyes por crear un embrión de política marítima de defensa de la costa y, muy especialmente, un medio de afirmación de la monarquía frente a los señores feudales ${ }^{19}$. El proceso de implantación de villas nuevas comenzó en 1155 con la fundación formal de Avilés y se multiplicó tras la separación de los reinos de Castilla y León, gracias a la actividad repobladora de Fernando II y Alfonso IX en la orla costera de León, de Alfonso VIII en la de Castilla y de Sancho VI el Sabio en la navarra.

${ }^{19}$ Solórzano 2007-2008, 2009a. 
En el reino de Castilla, el enlace de Alfonso VIII con Leonor de Inglaterra en 1170, hija de Enrique II y Leonor de Aquitania, que incluía la Gascuña como dote y el puerto de Santander como arras, necesitaba del fortalecimiento de la presencia regia en la costa para abrir el reino a los nuevos horizontes atlánticos y vincularlos con el gran espacios abarcado por el Imperio de los Plantagenet. Alfonso VIII y Leonor comenzaron otorgado fueros a cuatro puertos de la costa del reino: Santander (1187), Laredo (1200), Castro Urdiales (1202) y San Vicente de la Barquera (1210). La incorporación de Guipúzcoa al reino de Castilla en 1200, que contaba con el puerto de San Sebastián, fundado por el rey de Navarra, Sancho el Sabio, en 1200, fue reforzada por las concesiones forales de Alfonso VIII a Fuenterrabía (1203), Guetaria (1209) y Motrico (1209). En todos estos fueros se priman las relaciones comerciales e, incluso, algunos van acompañados de privilegios para la exportación de mercancías desde el interior meseteño, como es el caso de Castro Urdiales, en el que los reyes Alfonso y Leonor conceden al mismo tiempo el Fuero de Logroño y la exención de pagar portazgo en Medina de Pomar para las mercancías de los vecinos:

\begin{abstract}
Absolvo vos concilium de Castro de Urdiales, presens et futurum, quod de propris rebus vestris et mercaturis quas habeberas sine aliquo participe, qui non sit de vita vestra, nunquam in perpetuum detis portaticum in Medina de Pomar. Pretera concedo vobis forum de Lucronio perpetuo havendum ${ }^{20}$.
\end{abstract}

El objetivo era fortalecer el desarrollo del sector profesional de los mercaderes frente a cualquier competidor externo. Así, por ejemplo, se prohibía o limitaba la compraventa por menudo o al detalle a los extranjeros, excepto si habían obtenido licencia expresa para ello. Esta norma la hallamos en el fuero de Santander (1187): el que no fuere vecino de la villa no venda al detalle mercancía de paños traída por mar, a no ser a los hombres de la villa; $y$, si la vendiere a un forastero, pague 10 sueldos ${ }^{21}$.

En el reino de León, los reyes Fernando II (1157-1188) y Alfonso IX (1188-1230) también desplegaron enormes esfuerzos por fundar puertos en el litoral gallego y asturiano, que fueran capaces de neutralizar la influencia de la mitra compostelana y las sedes episcopales de Oviedo y Mondoñedo, asî como el de los señoríos laicos. En Asturias, la primera villa fundada fue Avilés en 1155, seguida de los puertos gallegos de Noya (1168) y Pontevedra (1169), aunque pronto pasaron a depender de la sede compostelana. Alfonso IX creó

${ }^{20}$ Archivo Foral de Vizcaya, Archivos de Familia, Familia Villaria 2702.

${ }^{21}$ Solórzano 2002, p. 293. 
Ribadeo en 1182, Viveiro (1190?), Laguardia (ca. 1200), Bayona (1201), Betanzos (1219), La Coruña (1208), el puerto de realengo gallego más importante, seguido por Llanes (hacia 1225) y Pravia (hacia 1230). Tras la unificación de Castilla y León en 1230, Fernando III concentró su esfuerzo en la concesión de privilegios económicos y su hijo, Alfonso X, aforó Ortigueira (1255), con un privilegio con importantes concesiones económicas, como la creación de una feria y la exención del portazgo a ciertos mercaderes. A este puerto le siguieron Cedeira, Puentedeume, Ferrol y Muros en la costa gallega ${ }^{22}$, y, en la asturiana, Llanes (1268), Gijón (1270), Valdés (Luarca), Roboredo y Maliayo (Villaviciosa) $^{23}$. A Alfonso X se le atribuye la fundación de Ribadesella, Candás y Luanco, y, a caballo entre el siglo XIII y principios del XIV, aparecieron otras dos villas portuarias: Navia y Ribadesella.

La región cantábrica que más tardó en incorporarse al proceso de fundación de puertos fue Vizcaya, precisamente porque era un territorio señorial. Con la creación de Bermeo en 1236, Vizcaya entró en las rutas del Atlántico como puerto de embarque de las mercancías del interior. Sin embargo, la fundación de otros puertos entre finales del siglo XIII y principios del XIV, supuso una reducción de su predominante papel en el comercio en la costa vizcaína. Plencia se fundaba a orillas del río Butrón en 1299, Bilbao en la ría del Nervión en 1300, Portugalete en 1322 al final de esa misma ría, Lequeitio en 1325 en la ría del Lea y, Ondárroa en la ría del Artibai en 1327. La competencia entre estos puertos los llevó a cierta especialización. Así, Bermeo, Lequeitio y Ondárroa se concentraron en la la actividad pesquera. Portugalete compaginó el comercio con la pesca y Bilbao acabó erigiéndose como el gran centro comercial del sector oriental del Cantábrico ${ }^{24}$.

Este proceso de creación de villas portuarias en el litoral atlántico del norte peninsular fijó una nueva organización del territorio, presidida por las villas de realengo, en un espacio que tradicionalmente había sufrido una fuerte implantación señorial. Por otra parte, los nuevos puertos servían para engrosar las arcas regias gracias a las actividades marítimas. El ordenamiento de aduanas de los puertos castellanos de las Cortes de Jerez de 1268 permite obtener una imagen de la jerarquización temprana de los puertos del Cantábrico según su papel como centros canalizadores del tráfico mercantil en el reino. De oeste a este, estas villas eran San Sebastián, Fuenterrabía, Castro Urdiales, Laredo, Santander, Avilés, Ribadeo, Viveiro, Betanzos, La Coruña, Santa María de

\footnotetext{
${ }^{22}$ Ferreira 2002, pp. 367-420.

${ }^{23}$ Ruiz de la Peña 1981, 1997, pp. 177-192.

${ }^{24}$ García de Cortázar, et al. 1985, pp. 25-36.
} 
Ortigueira, Cedeira, Ferrol, Bayona, La Guardia, Pontevedra, Padrón y Noya, donde además se nombra a mercaderes específicos ${ }^{25}$.

La fundación de nuevas villas portuarias se acompañó de la concesión de privilegios económicos y medidas proteccionistas, que fortalecieron las relaciones entre la monarquía y los puertos. Por una parte, los reyes otorgaron exenciones generales de impuestos a los vecinos. En 1280, Alfonso X concedió un privilegio a los vecinos de Fuenterrabía eximiéndoles de cualquier pecho y pedido, excepto el del diezmo con la finalidad de que se "pueble mejor"26. Igualmente, los monarcas ayudaron a consolidar unas élites emergentes, enriquecidas por las actividades marítimas. Por ejemplo, los monarcas permitieron la mediación de los mercaderes en los beneficios de la fiscalidad regia. Uno de los derechos reales más importantes consistía en la renta de las ferrerías. En 1257, Alfonso X arrendó los derechos reales de las ferrerías de la región cantábrica, desde Asturias de Santillana hasta Fuenterrabía, por 15.000 mrs. durante cinco años, a dos mercaderes de Santander, Pero Pérez de Pámanes y Domingo Pérez, quienes mantenían fuertes vínculos con el entorno de la corte regia, pues éste último era dependiente de don Sancho, abad de Santander, electo de Toledo, chanciller y hermano del rey. La preocupación regia por el fomento de las actividades mercantiles en los puertos del Cantábrico llega hasta finales de la Edad Media. En 1503, la reina Isabel I concedió a La Coruña el privilegio de feria franca con una duración de treinta días, con lo que se buscaba atraer a los mercaderes foráneos por medio de ventajas fiscales. Este tipo de privilegios suponía un gran impulso a las economías urbanas de los puertos ${ }^{27}$.

Los diezmos de la mar fueron una de las rentas más sabrosas de la corona castellana hasta su enajenación por Enrique IV $^{28}$. La llegada a Castro Urdiales, Laredo, Santander y San Vicente de la Barquera de las mercancías del Atlántico, gravadas con el diez por ciento de su valor, al igual que las que salían del reino, suponía una fuente de ingresos de primera magnitud. En este punto puede verse la competencia entre los puertos vascos y cántabros con los gallegos y asturianos cuando en 1448 los arrendadores de los diezmos de la mar denunciaron el fraude que suponía el desvío de mercancías de los puertos del Cantábrico oriental al occidental con la finalidad de no pagar por las mercancías en los puertos aduaneros vinculados a Burgos, que provocaba una rebaja del $80 \%$, lo que causaba un gran daño a las arcas regias ${ }^{29}$.

\footnotetext{
${ }^{25}$ Cortes de los antiguos reinos de León y de Castilla 1861, p. 74.

${ }^{26}$ Larrañaga, Tapia 1993, pp. 8-9.

${ }^{27}$ Ferreira 1988.

${ }^{28}$ Díez de Salazar 1983.

${ }^{29}$ Ibidem, p. 19.
} 


\section{INSTALACIONES E INFRAESTRUCTURAS PORTUARIAS}

Evidentemente, la geografía del litoral cantábrico tuvo una gran influencia en el éxito de unos puertos y la frustración de otros. Hubo algunos puertos cuyo desarrollo quedó frustrado, como fue el caso de Plencia en un primer momento. En la carta foral de 1299, Diego López V de Haro relataba que había ordenado crear Plencia en el mismo lugar donde lo había hecho antes su abuelo, Diego López II, fallecido en 1236, por lo que aquel primer intento de fundación debió ser en una fecha anterior a su muerte. Por este motivo, los concejos se preocuparon por contar con unas infraestructuras de comunicación suficientes para disminuir las desventajas de su ubicación, aunque no todos los concejos pudieron disponer de ellas, debido a lo costoso de su construcción y mantenimiento. Las dificultades de comunicación con el traspaís leonés y las escasas iniciativas por parte de los concejos portuarios explican el modesto desarrollo de los puertos asturianos, con la salvedad de Avilés. Este retraso contrasta con el desarrollo de las villas cántabras y vascas, muy interesadas en mantener las relaciones comerciales con las ciudades interiores de Vitoria y Burgos.

La mayor parte de los puertos del Cantábrico, a excepción de los gallegos, se hallan en la línea de la costa, protegidos en el mejor de los casos, por un cerro. Pocos fueron los puertos que dispusieron de un muelle y unas infraestructuras portuarias adecuadas hasta el siglo XV, ya que la carga y descarga de mercancías se realizaban por medio de barcas de menor calado, que trasportaban las mercancías y las personas desde los navíos anclados en alta mar hasta los puertos. Las primeras infraestructuras sólidas están vinculadas al almacenamiento de mercancías, como lonjas, alfonies de sal, trigo y hierro, casas del peso. Este tipo de almacenes está documentado en La Coruña, Pontevedra, Avilés, Santander, Laredo, Lequeitio, Bilbao, Plencia y San Sebastián.

Sin embargo, sólo las villas portuarias del sector centro-oriental del Cantábrico, aquel que estaba más vinculado al traspaís burgalés, construyeron muelles o cays de piedra en el siglo $\mathrm{XV}$, que resultaron ser las más pujantes en el comercio internacional. En el siglo XV y principios del XVI, se documentan los cays o muelles viejos de Santander (1434), San Sebastián (1440), Laredo (1460), Bilbao (1470), Avilés (1488), Pasajes (1497), Lequeitio (s. XV), Guetaria (1500), San Vicente de la Barquera (1500), Portugalete (1502), Castro Urdiales (1508) y Bermeo (1510), entre otros. En cuanto a los puertos gallegos, las únicas instalaciones portuarias son los peiraos, los puentes, que servían de muelle de carga y descarga directa entre la nave y los carros situados sobre el camino, como se documentan en Vivero, Santa Marta de Ortigueira, Cedeira, Neda, Betanzos, Puentedeume, Noya, Padrón, Pontevedra y Redondela. Respecto a las villas asturianas, salvo en Avilés, no se levantaron 
infraestructuras portuarias hasta el siglo XVI. Sabemos de este muelle porque la barra del cay tuvo que ser reparada en 1488 , ya que se hallaba derruida e impedía la entrada de los barcos:

De çierto tiempo a esta parte se le ha çerrado e çierra la barra y canal por donde las dichas naos han de venir e entrar en la dicha villa, a cabsa de un cay que de tiempo ynmemorial tenían, el qual diz que se les ha desbaratado e derrocado [...] a cabsa de lo suso dicho estar derribado e desbartado, diz que non pueden entrar allí naos nin navíos ningunos, por non tener agoa que les baste ${ }^{30}$.

De este modo, la construcción de infraestructuras portuarias en las villas comprendidas entre Avilés y Fuenterrabía en el siglo XV configuró una nueva jerarquización portuaria, más dinámica y competitiva en el Cantábrico oriental que en el occidental.

\section{LA INTERVENCIÓN Y EL CONTROL PORTUARIO DEL ESPACIO COSTERO}

Dada la vital importancia del mar para las sociedades portuarias, el control del espacio marítimo, como área de expansión exclusiva, fue un factor de éxito de cada uno de los puertos del Cantábrico, que establecieron un férreo control sobre las aguas del litoral con el objetivo de intervenir sobre el tráfico marítimo y el aprovechamiento pesquero en la rica zona de la estrecha plataforma continental. Las cartas forales y privilegios posteriores incluyeron el mar como linde y no como parte de la jurisdicción de los puertos, lo que generó numerosos conflictos entre los puertos con el objetivo de controlar la carga y descarga de mercancías. Así, la carta foral de Plencia de 1299 delimitaba el término jurisdiccional, incluyendo la costa y las aguas:

E otorgobos que ayades por terminos desde como toma el bocal de Gorliz, ribera de la mar, asta el Çomo de junto Hermua, dentro, y dende a Andraca e Albaro de Arribay, e de Gana fasta el termino de Santa Maria de Barrica, que hes ribera de la mar, con todas las anchuras y exidos e montes y aguas e lugares que en los dichos terminos ay asi como don Lope Diaz, mi aguelo, los ubo dado amojonados quando esta puebla hizo ${ }^{31}$.

En 1478, el puerto de San Vicente de la Barquera, por ejemplo, detuvo a un vecino del valle de Cabuérniga y quemó su nave por haber descargado pan y otras mercancías sin permiso del concejo:

${ }^{30}$ Sanz, Álvarez, Calleja 2011.

${ }^{31}$ Enríquez Fernández 1988, Doc. 1. 
Los vesinos de la dicha villa de San Vicent venieron e tomaron e levaron el dicho navio con el dicho pan en su poder; e lo quemaron por causa de faser la dicha descarga del dicho pan alli, sin demandar lecencia al dicho concejo de la dicha villa, disiendo que era fecho en quebrantamiento de los privillejos e usos e costumbres del dicho concejo de la dicha villa ${ }^{32}$.

El control de la jurisdicción del litoral cantábrico fue un motivo de disputa entre los puertos o entre estos y las villas del interior que no disponían de acceso al mar, e incluso en la frontera de Castilla con los reinos de Francia y Portugal. Es el caso de la disputa entre Fuenterrabía y Hendaya por el control de las aguas del río Bidasoa que comenzó a mediados del siglo XV, cuando el reino de Francia ordenó construir una torre en la orilla de la parte francesa, aunque Castilla entendía que ambas orillas pertenecían a la villa de Fuenterrabía, ya que al tener la jurisdicción sobre el río, también se incluía toda la tierra que tocaba su agua. Así lo entendía Castilla:

\begin{abstract}
asy el rio, que llaman de Vidassoa, commo el puerto e mar e figuer e concha commo se navegan e passan desta parte a la parte de Francia, es de la corona rreal de vuestra magestad de tiempo inmemorial a esta parte; e por tal es avido e tenido e por todos conocido, llevando vuestra alteza los derechos del diezmo viejo e prebostazgo e anclage e sysa e lonja e todos los otros derechos que se suelen e acostumbran a llevar en los otros puertos, syn tener que entender en ello ni en parte alguna dello el Rrey de Françia ${ }^{33}$.
\end{abstract}

El conflicto se solucionó por una concordia, sellada en 1510, según la cual los vecinos de Hendaya sólo podrían usar la ría para uso personal, pero en ningún caso para la pesca comercial. Además, los barcos de Hendaya no podrían usar quilla, lo que les impedía salir al mar. Precisamente, el puerto de Fuenterrabía también tuvo numerosos problemas con la vecina villa de San Sebastián. Uno de tantos se produjo en 1502, cuando Fuenterrabía quiso construir una torre en la ría para la defensa de su puerto a lo que San Sebastián se opuso. Fuenterrabía se quejaba, además, de que San Sebastián obligaba a que todos los barcos descargaran en su puerto, por lo que siempre estaba mal proveída $^{34}$. Conflictos similares mantuvieron las villas de Ribadeo y Roboredo, San Sebastián con Fuenterrabía y Rentería, Laredo con Santoña, San Vicente de la Barquera con Comillas, Santander con Santillana, etc., de los que unos puertos salieron más fuertes que otros. Por ejemplo, Santander era un puerto

\footnotetext{
${ }^{32}$ Solórzano, Fernández González 1996, p. 30.

${ }^{33}$ Rodríguez de Diego, Zabalza 2012, p. 61.

${ }^{34}$ Ibidem, p. 45.
} 
privilegiado del Cantábrico debido a su ubicación central en el litoral, su gran bahía, un amplio estuario y su accesibilidad al gran centro comercial de la ciudad de Burgos. Santillana del mar, capital de la merindad de las Asturias de Santillana y del Marquesado desde 1445, necesitaba un puerto por el que conectarse con las rutas marítimas y entabló un largo pleito con Santander para controlar el puerto de Suances en la ría de San Martín de la Arena, situado a unos 15 kilómetros de Santander y, dentro de la jurisdicción marítima de Santander, aunque no terrestre. Santander emprendió un pleito entre 1434 y 1436 , que le confirmó su jurisdicción y que utilizó como puerto adicional, aunque sobre todo para impedir que Santillana, la capital de la merindad menor del mismo nombre, se apropiara de él. Esto le aseguró el desarrollo comercial, como lo prueba el beneficioso acuerdo entre Santander y la Universidad de Mercaderes de Burgos en 1453, justo en un momento de fuerte disputa entre Bilbao y Burgos por el control del comercio atlántico en Brujas.

Otros puertos siguieron el ejemplo de Santander, Laredo y Castro Urdiales. En 1504, el concejo de San Vicente de la Barquera alegaba que

porque la villa de Santander que esta a diez leguas de la dicha villa tier privilegios y costumbre de que cinco leguas alrededor de cada parte, ningún cargo o descargo ni pesquería se pueda hazer en muchos puertos que ay çerca della, y que esto mismo tienen las villas de Laredo e Castro Ordiales

para defender su privilegio de las cuatro leguas del que habían disfrutado y que le disputaban los lugares de Ruiloba, Novales, Cóbreces y Ruiseñada ${ }^{35}$. Así, los puertos del Cantábrico crearon unos términos jurisdiccionales que incluían tanto la tierra como el mar, que servía para regular la comercialización de las mercancías a través de sus puertos, aprovecharse de los recursos pesqueros de bajura y controlar la navegación de cabotaje.

\section{El PAPEL DE LOS PUERTOS DEL CANTÁBRICO \\ EN LA MARITIMIZACIÓN DEL NORTE PENINSULAR}

Tras haber analizado los distintos factores físicos y políticos que impulsaron la constitución de la red urbana a lo largo del litoral cantábrico, se va a analizar en este apartado el proceso de "maritimización" del norte peninsular, es decir, cómo se incrementó la influencia del litoral en la economía del norte de la Corona de Castilla, fundamentalmente del área comprendida entre Burgos y los puertos del sector oriental del Cantábrico, entre los siglo XIII y XV.

\footnotetext{
${ }^{35}$ Sainz Díaz 1986, p. 198.
} 
Tras su creación, al mismo tiempo que se iban consolidando los puertos, los mercaderes actuaron como agentes que generaban y modificaban el consumo y la producción de sus poblaciones. Desde el siglo XIII, el comercio internacional, muy competitivo, estaba en manos privadas. Este comercio estaba dirigido por los mercaderes que crearon amplias coaliciones mercantiles en distintos puertos. La acción de los agentes mercantiles se plasmó, pues, en unas conexiones interurbanas, que en los siglos XIII y XIV, fueron muy importantes para regular la actividad mercantil en ausencia de instituciones.

Los primeros vínculos comerciales entre los mercaderes del Cantábrico y los puertos europeos datan de principios del siglo XIII, en concreto, se documenta el puerto de La Rochelle, en 1224, que era frecuentado por los mercaderes que navegaban hasta Inglaterra y Flandes ${ }^{36}$. En estos mismos años, aparecen mercaderes de San Sebastián en los puertos del sur de Inglaterra, que se consolidarán aun más desde el matrimonio de Leonor de Castilla con el rey inglés Eduardo I y la firma del tratado anglo-castellano de 1254. La rentabilidad del comercio de los puertos del Cantábrico se evidenció con la creación por Alfonso X del diezmo de la mar de Castilla, que gravaba con un $10 \%$ todas las mercancías que entraran y salieran por estos puertos ${ }^{37}$. Según las cuentas del diezmo aduanero de 1293 y 1294, las Cuatro Villas de la Costa de la Mar habían recogido más del doble que las guipuzcoanas, en concreto, 65.508 y 64.973 mrs., respectivamente, correspondiendo a Santander el 46\% de la recaudación de las Cuatro Villas de la Costa, lo que nos informa que era el puerto más activo del Cantábrico a finales del siglo XIII, antes justo de la fundación de Bilbao en $1300^{38}$. Entre los productos importados se encontraban más de cincuenta variedades de paños, productos alimenticios, quincallería, buhonería, vestidos, adornos, tintes y ganado procedentes de Flandes, Inglaterra y Francia con dirección a los puertos y al interior de la Meseta ${ }^{39}$. El diezmo de la mar de 1293 nos informa de las relaciones comerciales entre la costa cantábrica y, fundamentalmente, los centros urbanos del Atlántico, como Abbeville, Arras, Bailleul, Caen, Cambray, Commines, Douai, Gante, Langemarck, Lille, Lincoln, Montreuil, Parthenay, Poperinghe, Provins, Reims, Ruán, Saint Omer, Tournai e Yprès; en menor medida se documentan los puertos del Mediterráneo, como Montpellier y Venecia. A partir de la primera mitad del siglo XIV, se hicieron muy frecuentes las naves del Cantábrico oriental en el puerto de Mallorca, como revelan los registros del "ancoratge", con la arribada de cocas de Bermeo, Castro Urdiales, Fuenterrabía, Guetaria, Lequeitio, San

\footnotetext{
${ }^{36}$ Tranchant 2003.

${ }^{37}$ Díez de Salazar 1983.

${ }^{38}$ Gaibrois 1922; Hernández 1993.

${ }^{39}$ Castro 1921, pp. 325-356.
} 
Sebastián y Santander ${ }^{40}$. A finales de esa centuria, en 1385, el $42 \%$ de los barcos que arribaban a Londres pertenecían a mercaderes castellanos y a finales del siglo XV se documentan 480 mercaderes castellanos viviendo en Bristol, Londres, Southampton y Sandwich. La principal mercancía exportada desde Inglaterra era la ropa, seguido del grano, el cuero, el pescado, el estaño, piezas artísticas, joyas y libros, mientras que por los puertos del Cantábrico salían vino, especias, aceite, seda, y lana ${ }^{41}$. Además, los barcos del Cantábrico transportaban mercancías entre Francia, Inglaterra, Flandes, Andalucía e Italia. Las mercancías importadas por los puertos del Cantábrico no sólo se distribuían hacia las ciudades de la Meseta, sino también entre los propios puertos y aldeas del interior. Así, en 1527, el mercader Diego Hernández de Loredo, vecino de la Merindad de Trasmiera, compró, a Doña María Díaz de Salvatierra y su hija, unas piezas de cozneos, importadas de Nantes, en la feria de Santiago de Bilbao, que transportó en una pinaza hasta Santander para venderlas en la aldea de Loredo y a quienes denunció después por fraude de calidades ${ }^{42}$.

Por ejemplo, las conexiones de las Cuatro Villas de la Costa de la Mar entre los siglos XIII y XV abarcaban (tabla 1), en primer lugar los puertos del Cantábrico, desde Bayona hasta Irún, seguidos por los puertos atlánticos y, en menor medida, por los del Mediterráneo, infiltrándose en las rutas catalanas como transportistas ${ }^{43}$. Uno de los principales productos comercializados en el Cantábrico era la sal, que era suministrada por Galicia, junto con pescado, a los puertos asturianos y cántabros. Desde el alfoní o depósito de Santander se distribuía la sal, desde al menos 1338, siendo junto con Laredo, Castro Urdiales y San Vicente de la Barquera uno de los principales centros proveedores de Castilla para Burgos, Palencia, Carrión, Valladolid, Sahagún y toda la Tierra de Campos ${ }^{44}$, lo que trajo consigo el inevitable enfrentamiento de estas villas con Salinas de Añana, conflicto que llega hasta 1535, resultando todas las sentencias favorables al comercio de la sal de los puertos con Castilla ${ }^{45}$. Junto con la sal, también se exportaba pescado al interior, en especial a Burgos, que se proveía de pescado capturado en la costa oriental del Cantábrico ${ }^{46}$. Desde los puertos cántabros, además, se exportaban productos de hierro manufacturado y madera hacia los puertos del Cantábrico occidental. Por otro lado, los puertos vascos exportaban hierro y lana hacia Cantabria, Asturias y Galicia.

\footnotetext{
${ }^{40}$ Ferrer 2003, p. 116.

${ }^{41}$ Childs 1978,pp. 154-178; Childs 2003,pp. 55-64.

${ }^{42}$ Archivo de la Real Audiencia y Chancillería de Valladolid, Reales Ejecutorias, c. 395/18.

${ }^{43}$ Ferreira 2003, pp. 9-46.

${ }^{44}$ González Díez 1984, doc. 190bis.

${ }^{45}$ Solórzano 1995, docs. 8, 15, 146, 147, 148, 195, 196, 198, 200, 205, 217, 228, 247.

${ }^{46}$ Sebastián 2017, p. 506.
} 


\begin{tabular}{|c|c|c|c|}
\hline & CANTÁBRICO & ATLÁNTICO & MEDITERRÁNEO \\
\hline $\begin{array}{l}\text { Castro } \\
\text { Urdiales } \\
(1246-1520)\end{array}$ & \begin{tabular}{|l|} 
Asturias, Avilés, Bayona, \\
Betanzos, Bilbao, \\
Candemiro, Cedeira, \\
Deva, El Ferrol, Finisterre, \\
Fuenterrabía, Galicia, \\
Gijón, Gordón, Grado, \\
Guetaria, Guipúzcoa, Puebla \\
de Hea, Hondárroa, La \\
Coruña, Laguardia, Laredo, \\
Lequeitio, Llanes, Luarca, \\
Lugo, Maliayo, Miño, \\
Motrico, Munguía, Muros, \\
Musquiz, Navia, Noya, \\
Orduña, Orense, Oriñón, \\
Oyarzun, Padrón, Pasajes, \\
Plencia, Pontevedra, \\
Portugalete, Pravia, \\
Purón, Rentería, Ribadeo, \\
Ribadavia, Ribadedeva, \\
San Sebastián, San Vicente \\
de la Barquera, Bermeo, \\
Santa Marta, Santander, \\
Somorrostro, Tuy, Valdés, \\
Viveiro, Vizcaya, Zumaya \\
\end{tabular} & $\begin{array}{l}\text { Abbeville, Aquitania, } \\
\text { Arras, Bailleul, Bayona, } \\
\text { Borgoña, Biarritz, } \\
\text { Brabante, Breage } \\
\text { (Cornualles), Bretaña, } \\
\text { Bristol, Brujas, Burdeos, } \\
\text { Cádiz, Caen, Cambray, } \\
\text { Commines, Capbreton, } \\
\text { Douai, Estaple, Flandes, } \\
\text { Francia, Gante, Gascuña, } \\
\text { Holanda, Huelva, } \\
\text { Inglaterra, Isla de Jersey, } \\
\text { Irlanda, Langemarck, } \\
\text { La Punta, La Rochelle, } \\
\text { Lille, Lincoln, Montreuil, } \\
\text { Parthenay, Poperinghe, } \\
\text { Lisboa, Londres, } \\
\text { Plymouth, Portsmouth, } \\
\text { Promphill (Kent), Ruán, } \\
\text { Saint Omer, Southampton, } \\
\text { Tournai, San Juan de } \\
\text { Luz, Sandwich, Sevilla, } \\
\text { Westminster, Zelanda, } \\
\text { Yprès, Zwyn }\end{array}$ & $\begin{array}{l}\text { Barcelona, } \\
\text { Cartagena, } \\
\text { Elche, Florencia, } \\
\text { Génova, } \\
\text { Mallorca, } \\
\text { Montpellier, } \\
\text { Murcia, Valencia }\end{array}$ \\
\hline $\begin{array}{l}\text { Laredo } \\
(1200-1520)\end{array}$ & \begin{tabular}{|l|} 
Asturias, Avilés, Bayona, \\
Bermeo, Betanzos, Bilbao, \\
Candemiro, Castro Urdiales, \\
Cedeira, Deva, Ferrol, \\
Finisterre, Fuenterrabía, \\
Galicia, Gijón, Guetaria, \\
Guipúzcoa, La Coruña, \\
Lequeitio, Llanes, Luarca, \\
Malpica, Marín, Miño, \\
Motrico, Munguía, Muros, \\
Musquiz, Navia, Noya, \\
Ondárroa, Ongallo, Oriñón, \\
Oyarzun, Pasajes, Plencia, \\
Pontedeume, Pontevedra, \\
Portugalete, Pravia, Purón, \\
Rentería, \\
Ría de Arosa, Ribadesella, \\
Ribadedeva, Ribadeo, San \\
Sebastián, Santoña, San \\
Vicente de la Barquera, \\
Santander, Sevilla, Tuy, \\
Valmaseda, Viveiro, \\
Vizcaya, Zumaya
\end{tabular} & $\begin{array}{l}\text { Abbeville, Amberes, } \\
\text { Andalucía, Arras, Bailleul, } \\
\text { Bayona, Beleisa, Biarritz, } \\
\text { Bretaña, Bristol, Brujas, } \\
\text { Burdeos, Caen, Cambray, } \\
\text { Commines, Capbretón, } \\
\text { Cornwall, Dartmouth, } \\
\text { Devon, Dinamarca, } \\
\text { Dorset, Douai, Escocia, } \\
\text { Flandes, Francia, Galway } \\
\text { (Irlanda), Gante, Giçala } \\
\text { (Irlanda), Irlanda, Isla de } \\
\text { Morlaix, La Esclusa, La } \\
\text { Punta, Langemarck, La } \\
\text { Rochelle, Lille, Lincoln, } \\
\text { Montreuil, Parthenay, } \\
\text { Poperinghe, Lisboa, } \\
\text { Londres, } \\
\text { Middleburgo, Nantes, } \\
\text { Oporto, Palos, Plymouth, } \\
\text { Portugal, Prusia, Ruán, } \\
\text { Saint Nazaire, Saint } \\
\text { Omer, San Juan de Luz, } \\
\text { Somerset, Southampton, } \\
\text { Tournai, Torca (Irlanda), } \\
\text { Yoella (Irlanda), Yprès }\end{array}$ & $\begin{array}{l}\text { Barcelona, } \\
\text { Cartagena, } \\
\text { Gibraleón, } \\
\text { Granada, Ibiza, } \\
\text { Mallorca, } \\
\text { Marsella, } \\
\text { Montpellier, } \\
\text { Murcia, } \\
\text { Nápoles, } \\
\text { Piacenza, Pisa, } \\
\text { Rhodes, } \\
\text { Palermo, } \\
\text { Valencia, } \\
\text { Venecia, } \\
\text { Villefranche }\end{array}$ \\
\hline
\end{tabular}




\begin{tabular}{|c|c|c|c|}
\hline $\begin{array}{l}\text { Santander } \\
(1226-1520)\end{array}$ & $\begin{array}{l}\text { Avilés, Baracaldo, Bayona, } \\
\text { Bermeo, Betanzos, Bilbao, } \\
\text { Candemiro, Castro Urdiales, } \\
\text { Cedeira, Deva, El Ferrol, } \\
\text { Finisterre, Fuenterrabía, } \\
\text { Fuenterrabía, Galicia, } \\
\text { Gijón, Gordón, Guetaria, } \\
\text { Guipúzcoa, Fuenterrabía, } \\
\text { La Coruña, Lequeitio, } \\
\text { Llanes, Luarca, Malpica, } \\
\text { Mión, Motrico, Munguía, } \\
\text { Muros, Musquiz, Navia, } \\
\text { Noya, Ondárroa, Ongallo, } \\
\text { Oriñón, Oyarzun, Pasajes, } \\
\text { Plencia, Pontedeume, Purón, } \\
\text { Pontevedra, Portugalete, } \\
\text { Pravia, Rentería, Ría } \\
\text { de Arosa, Ribadeo, } \\
\text { Ribadesella, San Martín de } \\
\text { la Arena, San Sebastián, } \\
\text { San Vicente de la Barquera, } \\
\text { Santa Marta, Santurce, } \\
\text { Tuy, Valmaseda, Viveiro, } \\
\text { Vizcaya, Zarauz, Zumaya }\end{array}$ & $\begin{array}{l}\text { Abbeville, Alemania, } \\
\text { Andalucía, Arras, Bailleul, } \\
\text { Barrameda, Bayona, } \\
\text { Bristol, Biarritz, Brujas, } \\
\text { Burdeos, Caen, Cagliari } \\
\text { (Cerdeña), Cambray, } \\
\text { Commines, Capbretón, } \\
\text { Conventry, Dartmouth, } \\
\text { Douai, Dover, Escocia, } \\
\text { Flandes, Francia, } \\
\text { Gante, Langemarck, } \\
\text { Gascuña, Hauenemouth, } \\
\text { Inglaterra, Irlanda, Isla } \\
\text { de Wight, Jerez de la } \\
\text { Frontera, La Punta, La } \\
\text { Rochelle, Lille, Lincoln, } \\
\text { Montreuil, Nantes, } \\
\text { Parthenay, Poperinghe, } \\
\text { Lisboa, Londres, Oporto, } \\
\text { Portmouth, Redón, Ruán, } \\
\text { Saint Omer, Tournai, San } \\
\text { Juan de Luz, Sandwich, } \\
\text { Sevilla, Southampton, } \\
\text { Yprès, Zelanda }\end{array}$ & $\begin{array}{l}\text { Barcelona, } \\
\text { Cataluña. } \\
\text { Cerdeña, } \\
\text { Constantinopla, } \\
\text { Génova, } \\
\text { Granada, } \\
\text { Mallorca, } \\
\text { Marsella, } \\
\text { Montpellier, } \\
\text { Murcia, Sicilia, } \\
\text { Talamone } \\
\text { (Toscana), } \\
\text { Tarifa, Turquía, } \\
\text { Valencia, } \\
\text { Venecia, } \\
\text { Villefranche }\end{array}$ \\
\hline $\begin{array}{l}\text { San Vicente } \\
\text { de la } \\
\text { Barquera } \\
(1281-1520)\end{array}$ & $\begin{array}{l}\text { Asturias, Avilés, Baracaldo, } \\
\text { Bayona, Bermeo, Betanzos, } \\
\text { Bilbao, Candemiro, Castro } \\
\text { Urdiales, Cedeira, Cóbreces, } \\
\text { Comillas, Cudillero, Deva, } \\
\text { El Ferrol, Finisterre, } \\
\text { Fuenterrabía, Galicia, } \\
\text { Guetaria, Guipúzcoa, } \\
\text { Irún, La Coruña, Laredo, } \\
\text { Lequeitio, Llanes, Luarca, } \\
\text { Maliayo, Malpica, Motrico, } \\
\text { Musquiz, Navia, Noya, } \\
\text { Novales, Ondárroa, } \\
\text { Ongallo, Oyarzun, Plencia, } \\
\text { Pontedeume, Pontevedra, } \\
\text { Portugalete, Pravia, Purón, } \\
\text { Rentería, Ribadedeva, } \\
\text { Ribadesella, Ribadeo, } \\
\text { Ruiloba, Ruiseñada, San } \\
\text { Sebastián, Santa Marta, } \\
\text { Santander, Santiurde, } \\
\text { Valmaseda, Viveiro, } \\
\text { Vizcaya, Zumaya }\end{array}$ & $\begin{array}{l}\text { Abbeville, Andalucía, } \\
\text { Arras, Bailleul, Bayona, } \\
\text { Berbería, Biarritz, } \\
\text { Bretaña, Brujas, Cádiz, } \\
\text { Caen, Coava (Portugal), } \\
\text { Combe Martin, Capbreton, } \\
\text { Commines, Douai, } \\
\text { Flandes, Francia, Gante, } \\
\text { Gascuña, Inglaterra, } \\
\text { Irlanda, Isla de Groix } \\
\text { (Bretaña), Jerez de la } \\
\text { Frontera, La Punta, } \\
\text { Langemarck, Larache, } \\
\text { Lille, Lincoln, Montreuil, } \\
\text { Parthenay, Poperinghe, } \\
\text { Londres, Portugal, Puerto } \\
\text { de Santa María, Rota, } \\
\text { Ruán, Saint Gilles, Saint } \\
\text { Omer, Tournai, San Juan } \\
\text { de Luz, Terranova, Yprès }\end{array}$ & $\begin{array}{l}\text { Berbería, } \\
\text { Granada, } \\
\text { Montpellier, } \\
\text { Murcia, } \\
\text { Venecia }\end{array}$ \\
\hline
\end{tabular}

Tabla 1. Las conexiones interurbanas de las Cuatro Villas de la Costa de la Mar (siglos XIII-XV). Elaboración propia. 
En el norte peninsular, los puertos y sus mercaderes constituyeron instituciones, como la Hermandad de la Marina de Castilla. Los puertos del Cantábrico acordaron aliarse con un doble objetivo claro: la protección mutua y la prosperidad mercantil. En 1296, se creó la Hermandad de la Marina de Castilla, una institución que integraba a los ocho puertos más dinámicos del Cantábrico -Santander, Laredo, Castro Urdiales, San Vicente de la Barquera, Bermeo, Guetaria, San Sebastián y Fuenterrabía- con la ciudad de Vitoria en el interior alavés. La capital de la hermandad se estableció en Castro Urdiales y entre los objetivos que marcó su carta fundacional se estableció la prohibición de comerciar con Bayona en la Guyena inglesa, con Inglaterra y con Flandes mientras durase la guerra con Francia, asegurar la paz y el comercio con Portugal, dirimir los conflictos internos de manera pacífica y guardar el señorío del rey en la costa. Esta hermandad sirvió para fortalecer el papel comercial del litoral cantábrico oriental, cuyos puertos se erigieron como centros de intermediación, al ser la única salida de los productos de la Meseta del reino de Castilla y servir a la navegación de cabotaje que unía el Mediterráneo y el Atlántico ${ }^{47}$.

A pesar del acuerdo, los agentes mercantiles no podían obviar los vínculos que mantenían con los puertos bajo autoridad inglesa, Bayona y Burdeos, que eran muy estrechos desde el XIII, como se manifiesta el salvoconducto obtenido por comerciantes y marineros castellanos en 1297 del rey Eduardo I ${ }^{48}$, o las treguas, como la suscrita en 1293 entre el rey de Castilla y la comuna de Bayona, o las establecidas por Castro Urdiales, Laredo y Santander, firmada en 1306 y 1309, al igual que hicieron los puertos guipuzcoanos en 1309,1311 y 1328 . Una petición del puerto de Bermeo de 1317, dirigida a al rey Eduardo I en nombre de todas las villas de Vizcaya para que no las atacasen, a pesar de estar los reinos de Castilla y de Inglaterra enfrentados, nos informa de que estos puertos del Cantábrico oriental desarrollaron su propia política de acuerdos, con el objetivo de sostener su influencia militar o comercial en los puertos ingleses y franceses, y eliminar la competencia de otras redes mercantiles, como la Hansa, que podrían haberse beneficiado del contexto internacional para introducirse en esos mercados.

La institución de la Hermandad de la Marina de Castilla tuvo una corta existencia, ya que desde el inicio de la Guerra de los Cien años, la acción de las villas portuarias frente al exterior fue asumida por los mercaderes, que se erigieron en representantes de cada una de las marismas o provinçias marítimas. La neutralidad castellana en la guerra hasta la derrota naval de

\footnotetext{
${ }^{47}$ Solórzano 2013,p. 160.

${ }^{48}$ Ibidem .
} 
Winchelsea de 1350 permitió que los mercaderes de la costa cantábrica hicieran buenos negocios en Flandes, Inglaterra y los puertos de poniente. En 1339, el mismo año en que Felipe VI Valois concedió ciertos privilegios a los mercaderes para atraerlos a Normandía ${ }^{49}$, se crearon hermandades menores como la de Guetaria, San Sebastián y Motrico, lo que llevó a una pérdida de la unidad de acción frente al exterior y a la fragmentación de la Hermandad de la Marina de Castilla ${ }^{50}$. Por parte del rey inglés Eduardo III de Inglaterra, durante los primeros años de guerra, llevó a cabo una política prudente respecto a Castilla al objeto de evitar represalias en Bayona, que le proporcionaba navíos de guerra ${ }^{51}$. En 1343, Juan IV de Bretaña firmó con los mercaderes vizcaínos un tratado comercial que abría este mercado a las lanas y hierros. Este statu quo que beneficiaba a los mercaderes del Cantábrico se rompió en 1350 con la victoria inglesa de Winchelsea sobre el convoy castellano procedente de Flandes y con el inicio de la guerra de corso de Bayona en la costa del Cantábrico ${ }^{52}$. Así, la segunda mitad del siglo XIV se iniciaba con los conflictos con Inglaterra. Al objeto de poner fin a un enfrentamiento que no beneficiaba a nadie, se establecieron varias concordias. En 1351 y 1353, se acordaron dos treguas entre el reino de Inglaterra y Toutes Marismes \& Costeres de Meer, Portz, Citees \& Villes de la Seignure le Rois de Castelle \& du Counte de Viscaye, con el fin de hacer prosperar el comercio e impedir que las naves castellanas del Cantábrico apoyaran a Francia. Como vemos, las villas portuarias miraban por sus propios intereses, firmando sus acuerdos y luego pidiendo el refrendo del rey, que al final siempre llegaba. Así sucede con la tregua de 1351 que fue confirmada por las Cortes de Valladolid de 1351:

A lo que me pedieron en rrazon dé la tregua que fue puesta entre el Rey de Ingraterra e los délas marismas de Castiella e de Guipuza e délas villas del condado de Vizcaya, que me pluguiesse ende. A esto rrespondo que me plaze e quelo tengo por bien ${ }^{53}$

El tratado de 29 de octubre de 1353 fue firmado en la parroquia de Fuenterrabía por Bayona y los procuradores de Castro Urdiales, Fuenterrabía, San Sebastián, Guetaria, Motrico y Laredo, en representación de la Hermandad, que preveía castigos a los malhechores ${ }^{54}$. El tratado de Libourne de 1366, rubricado entre Pedro I y el Príncipe Negro, dividió a los puertos de la

\footnotetext{
${ }^{49}$ Suárez 1959, p. 13.

${ }^{50}$ Solórzano 2013, p. 164.

${ }^{51}$ Suárez 1950, p. 7.

${ }^{52}$ Ibidem, pp. 38-39.

${ }^{53}$ Cortes de los antiguos reinos de León y Castilla, p. 7.

${ }^{54}$ Rymer 1740, vol. VI, pp. 717-719, 767-771.
} 
Hermandad, ya que una parte de la flota cantábrica, con intereses en Inglaterra, lo apoyó, pero Vizcaya y Guipúzcoa se levantaron en favor de Enrique II en 1367. Para la mayor parte de los mercaderes del Cantábrico la alianza con Inglaterra era vital para mantener el comercio con Flandes. Sin embargo, la alianza con Francia trajo varias victorias navales para los puertos del Cantábrico que conllevaron la apertura de los puertos atlánticos a las mercancías castellanas. De este modo, la mala relación de los puertos del Cantábrico con Enrique II pasó de la hostilidad a las buenas relaciones. Ciertamente, la alianza entre Francia y Castilla perjudicó seriamente los intereses en Flandes, pero unos años después, en 1384, Felipe II de Borgoña confirmó los privilegios de los castellanos ${ }^{55}$.

En 1404 y 1407 se sellaron dos grandes acuerdos que comprendían, por vez primera, a todos los puertos de la Marisma de Espanna con los puertos ingleses de La Gascuña para agilizar las relaciones mercantiles ${ }^{56}$. Así, en ambos aparece una cláusula especial que protegía mutuamente a los mercaderes y navegantes extranjeros, tanto en tiempo de guerra como de paz. En primer lugar, se establecía que si los reyes de Inglaterra y de Castilla entrasen en guerra, los mercaderes y maestres de navíos tendrían cuarenta días para poder marcharse en paz y, de otra, se acordaba que las villas portuarias de uno u otro lado de la frontera debían ofrecer seguridad con fianzas de que los extranjeros no sufrirían ningún daño. Además, estas dos concordias nos permiten conocer el grado de consolidación de las relaciones portuarias existentes en el litoral atlántico peninsular a principios del siglo XV. La Marisma de Espanna comprendía çinco provinçias o marismas: Guipúzcoa, Vizcaya, Castilla La Vieja, Asturias y Galicia, representadas por los procuradores de los concejos portuarios. El conjunto de puertos con conexiones más sólidas estaba integrado por las provinçias de las marismas de Castilla Vieja, Vizcaya y Guipúzcoa, mientras que las marismas de Asturias y Galiçia aparecían con una menor representación. En el acuerdo de 1404, se hallaban presentes los procuradores de San Vicente de la Barquera, Santander, Laredo, Castro Urdiales, Bermeo, Bilbao, Lequeitio, Ondárroa, Motrico, Deva, Zumaya, Guetaria y San Sebastián, en nombre de las provincias de Guipúzcoa, Vizcaya y Castilla Vieja, pero estaban ausentes los de los puertos de Asturias y Galicia, a pesar de estar incluidos en el acuerdo. En la concordia de 1407 , las villas portuarias gallegas y asturianas estaban presentes, si bien con solo tres procuradores en representación de los puertos de ambas provincias marítimas. La debilidad de representación hay que entenderla como

\footnotetext{
${ }^{55}$ Solórzano 2013, p. 229.

${ }^{56}$ Solórzano 1998, docs. 18-22.
} 
una fragilidad de las relaciones portuarias gallega y asturiana con el sector oriental del Cantábrico, salvo los puertos de Avilés y La Coruña. La explicación viene dada por la dualidad existente en Galicia y Asturias entre puertos de señorío y de realengo. Por una parte, los puertos gallegos de Pontevedra, Noya o Padrón estaban integrados en la órbita del arzobispo de Santiago, mientras los de Bayona y La Coruña pertenecían al realengo; en el ámbito asturiano, los puertos más importantes, como Luarca, Pravia, Cudillero, Gijón, Villaviciosa, Ribadesella pertenecían al conde de Noreña, cuyas posesiones limitaban con las del conde de Ribadeo a través del puerto de Navia, por lo que sólo Llanes y Avilés eran concejos independientes en este mundo señorializado. Por otra parte, el grado de integración y colaboración entre los mercaderes gallegos fue muy débil, pues nunca constituyeron hermandades similares a las del Cantábrico oriental, donde la jurisdicción del rey daba unidad al litoral, mientras que en Galicia los puertos del rey debían competir con los señoriales.

Guerra y diplomacia comercial fueron de la mano, motivo por el cual, las villas portuarias rechazaban las cartas de marca, ya que perjudicaban el comercio. A principios del siglo XVI, Bilbao se quejaba de que sus mercados estaban desabastecidos de productos de primera necesidad que importaban del extranjero y corría el riesgo de despoblarse, ya que los mercaderes extranjeros no se atrevían a ir a la villa a causa de las cartas de marca y represalia concedidas, ante lo cual la reina doña Juana amparó a los mercaderes extranjeros que abastecían Bilbao y anuló las cartas de represalia ${ }^{57}$. En 1488, los Reyes Católicos pidieron al corregidor de Guipúzcoa que informara sobre la costumbre que tenían Bayona, la Tierra de Lapurdi y Capbreton, de una parte, y las villas de Fuenterrabía y San Sebastián, de otra, de no ejecutar las cartas de marca y represalia en sus territorios ${ }^{58}$. Esto se debía a los continuos acuerdos firmados entre las villas guipuzcoanas y las gasconas a lo largo del siglo XV y hasta entrado el XVI. En 1432, San Sebastián firmó una tregua de dos años con Bayona, Biarritz, San Juan de Luz y Capbretón para que las embarcaciones de estas villas pudieran entrar y salir de manera segura, incluso en el caso de que la nave no perteneciera a una de estas villas, el salvoconducto debía respetarse si entre la tripulación hubiera vecinos de estos puertos ${ }^{59}$. Estos pactos entre villas particulares del Golfo de Vizcaya eran imprescindibles para la seguridad del comercio, de ahí su éxito.

Igualmente, el desarrollo económico de los puertos del Cantábrico hay que relacionarlo, por supuesto, con la expansión de las relaciones

\footnotetext{
${ }^{57}$ Enríquez, et al., 2000, p. 1021.

${ }^{58}$ Suárez 1966, p. 444.

${ }^{59}$ Ayerbe, et al., 2013, doc. 31.
} 
mercantiles y su inserción en los circuitos comerciales internacionales. En el siglo $\mathrm{XV}$, los mercaderes constituyeron las naciones y los consulados, instituciones que se encargaron de resolver de una forma más segura los conflictos, en especial sobre pagos. El establecimiento de colonias de mercaderes y consulados permitió reducir los costes de transacción, incrementar el nivel de confianza y de estabilidad emocional de los mercaderes, cerrar acuerdos, buscar productos, además de reforzar la solidaridad entre sus miembros en el extranjero e integrarse mejor en las sociedades de acogida ${ }^{60}$. El sistema de colonias y consulados tenía su origen en las ciudades italianas y se adaptó muy bien a los hábitos y necesidades de los mercaderes del norte peninsular.

Los mercaderes castellanos aparecieron tempranamente en Brujas. Los primeros en hacerlo fueron los mercaderes castellanos del Cantábrico, que aparecen documentados en el canal del Zwin en 1230. El privilegio más antiguo fue concedido el 26 de agosto de 1280 por el conde de Flandes, Guy de Dampierre a raíz de un problema surgido unos años antes, cuando los mercaderes castellanos y alemanes se habían quejado al conde de los abusos cometidos por Brujas en la imposición de peajes e hicieron un boicot que duró dos años, lo que demuestra que su posición comercial en Flandes era ya muy sólida. Los mercaderes se marcharon a Aardenbourg durante dos años con una carta de libertades del conde de Flandes para que no se fueran de Flandes. Esta carta de libertades sentó las bases de los futuros privilegios de los mercaderes en Brujas, pues les concedía cuatro cónsules para la defensa de sus intereses, y les garantizaba la seguridad de las personas y sus bienes, así como disponer de un sello ${ }^{61}$. La colonia recibía el nombre de la Nación de Vizcaya y de la costa marina de España en 1441. La principal mercancía de exportación desde Castilla fue la fina lana con destino al mercado de Flandes y, de retorno, la importación de productos flamencos como los textiles, mobiliario, tapices y objetos artísticos. En los primeros tiempos de la colonia en Brujas, los mercaderes y marinos se instalaron en hospederías, donde dormían, comían y depositaban sus mercancías en lonjas, como fue el caso del albergue de Jacques van der Beurse. Las gentes del Cantábrico estuvieron asentadas en torno a la Plaza de la Bolsa hasta 1434. A partir de esa fecha, abandonaron el régimen de pensión y se instalaron en sus propias casas, donde recibían a familiares, mercaderes, transportistas y marinos durante su estancia en Brujas. Los vizcaínos se asentaron en torno a la llamada Plaza de los Vizcaínos y a lo largo de la Reie, entre el puente de San Juan y el de la Grue y, en 1493, se les concedió oficialmente esta zona de Brujas como barrio propio para su mayor

\footnotetext{
${ }^{60}$ Casado Alonso, 2008, 2010, 2012.

${ }^{61}$ Solórzano 2013, 2015, p. 227; Gilliodts-Van Severen 1904, pp. 68-73; Vandewalle 2002; Rivera 2016.
} 
comodidad. La nación de los mercaderes del Cantábrico, la más antigua, entró en conflicto desde los años cuarenta del siglo XV con los mercaderes burgaleses asentados en Brujas, que adoptaron el nombre de la Nación de España. Esta agrupó a los mercaderes de Burgos, Sevilla, Toledo, Segovia, Soria, Valladolid, Medina del Campo, Logroño, Nájera, Navarrete y otras villas del interior del reino. Por su parte, la Nación de Vizcaya y de la Costa de España integraba a todos los mercaderes de la costa, desde Galicia hasta Guipúzcoa.

La fundación del Consulado de Burgos en julio de 1494, de la que iba a depender la Nación de España en Brujas, complicó las relaciones internas entre las colonias de mercaderes castellanos, ya que incluía bajo su jurisdicción todas las villas comprendidas desde la Merindad de Trasmiera hasta Fuenterrabía. Por una parte, los mercaderes del Cantábrico no tenían ninguna intención de estar controlados por los mercaderes burgaleses, y, por otra, éstos no deseaban depender de los armadores de la costa para el transporte marítimo de la lana ${ }^{62}$. Por esta razón, en Bilbao, el primer puerto en importancia del Cantábrico a finales del XV, el concejo, la cofradía de mercaderes y maestres de nao de Santiago y la Nación de la Costa de España de Brujas impulsaron el reconocimiento de un consulado propio con el objetivo de controlar las mercaderías del puerto. En 1495, los Reyes Católicos eximieron al Señorío de Vizcaya de la jurisdicción del consulado de Burgos y en 1499, se delimitaron las áreas de influencia, quedando bajo jurisdicción de la Universidad de Burgos las Cuatro Villas de la Costa de la Mar, e instituyendo una cofradía para las averías de Vizcaya, Guipúzcoa, las Encartaciones y Álava. La creación, en 1511, del Consulado de Bilbao, con las mismas competencias que el de Burgos, acabó por romper la unidad de acción de los mercaderes de los puertos de la costa oriental del Cantábrico ${ }^{63}$.

Los litigios entre Bilbao y Burgos jerarquizaron aun más la red portuaria en favor de Bilbao y perjudicaron los intereses del resto de las villas del Cantábrico, ya que ambos centros urbanos asumieron la representación del resto de puertos en el extranjero y Bilbao monopolizó los fletes. Por ejemplo, Portugalete se quejó de que las ordenanzas acordadas entre Bilbao y Burgos le perjudicaban su derecho de nombrar cónsules de Flandes y en Londres en nombre de la Nación de España, así como los fletes de las naos, que sólo podrían cargarse en el resto de villas del Cantábrico cuando se hubieran completado los fletes de Bilbao ${ }^{64}$.

Así pues, el sistema portuario del norte peninsular quedó dividido entre los puertos con una vocación claramente comercial e internacional,

\footnotetext{
${ }^{62}$ González Arce 2009, pp. 92-93.

${ }^{63}$ Guiard 1972, p. 7.

${ }^{64}$ Hidalgo, et al. 1987, Doc. 30.
} 
como Laredo, Santander, San Sebastián y La Coruña, liderados por Bilbao, $\mathrm{y}$, de otra, los puertos de menor tamaño, que combinaban las industrias de la pesca con el salazón, que era también un negocio muy rentable.

\section{CONCLUSIONES}

La estructura portuaria del comercio europeo entre los siglos XIII y XV se organizó de una forma jerárquica. El armazón estuvo constituido por los puertos de las grandes potencias marítimas y económicas, que eran el origen y destino de las grandes rutas mediterráneas y atlánticas, que estructuraban el tráfico mercantil internacional. Nos referimos a puertos como Génova y Venecia en un lado y Londres y Brujas en el otro extremo. En segundo lugar, existía un nivel intermedio de puertos que actuaba tanto en el ámbito regional, como en el tráfico marítimo internacional, ya que resultaban vitales en un sistema de navegación muy dependiente del cabotaje y las escalas como forma de aprovisionamiento e intercambio. Este es el caso de las villas portuarias del Cantábrico, que siendo puertos del nivel intermedio se constituyeron en polos de dinamización de la región cantábrica y en centros nodales del tráfico mercantil del reino de Castilla.

En la costa cantábrica se desarrollaron dos conjuntos de puertos, que no eran homogéneos. Por una parte, se hallaba las villas comprendidas entre Santander y Fuenterrabía, con una clara vocación internacional desde su fundación, lideradas por Bilbao en la segunda mitad del siglo XV, que podemos definir como un sistema urbano regional, debido a sus fuertes vínculos económicos, políticos y socio-culturales con continuidad espacial. Y, de otra, los puertos entre San Vicente de la Barquera y Bayona, dedicados en su mayor parte a la actividad pesquera y el transporte marítimo, donde sólo se destacan los puertos de Avilés y La Coruña, y que no se integraba en un sistema urbano regional propio, aunque en su conjunto, estableció vínculos con el resto de puertos. Así, podemos concluir que el conjunto del medio centenar de puertos del Cantábrico bajomedieval, a pesar de carecer de homogenidad, resultó un éxito porque se fundamentó sobre una serie de factores clave, tales como las condiciones geográficas, las infraestructuras y unas sociedades muy dinámicas, pero también a que, en estos puertos, periféricos por su ubicación, la política y la gobernanza adoptaron unas características comunes y distintas de las ciudades del interior peninsular para responder a las necesidades y condiciones locales, muy influidas por su carácter de frontera marítima de la Corona de Castilla. 


\section{BIBLIOGRAFÍA CITADA}

Andrade, Amélia Aguiar; Arízaga, Beatriz; Bochaca, Michel; Jean-Marie, Laurence; Kowaleski, Maryanne; Laget, Frédérique; Limberger, Michel; Miranda, Flavio; Solórzano, Jesús; Tranchant, Mathias (2016), La maritimisation du monde, de la préhistoire à nos jours. Enjeux, objets et méthodes, en La maritimisation du monde, de la préhistoire à nos jours. Enjeux, objets et méthodes, París, Presses de l'Université Paris-Sorbonne, pp. 29-50.

Arízaga Bolumburu, Beatriz; Solórzano Telechea, Jesús Ángel (eds.) (2005), Ciudades y villas portuarias del Atlántico en la Edad Media, Logroño, Instituto de Estudios Riojanos.

Ayerbe Iríbar, Rosa María; Irixoa Cortés, Iago; Lema Pueyo, José Ángel; San Miguel Osaba, Ana; Moya, Jesús (2013), Colección documental del Archivo Municipal de Hondarribia. Tomo III (1374-1480), San Sebastián, Sociedad de Estudios Vascos.

Bal, Mieke (2002), Travelling Concepts in the Humanities: A Rough Guide, Toronto, University of Toronto Press.

Bengoetxea Rementería, Belén; Quirós Castillo, Juan A. (2006), Las villas vascas antes de las villas. La perspectiva arqueológica sobre la génesis de las villas en el País Vasco, en Arízaga Bolumburu, Beatriz; Solórzano Telechea, Jesús Ángel (eds.), El Espacio Urbano en la Europa Medieval, Logroño, Instituto de Estudios Riojanos, pp. 147-165.

Blockmans, Wim (1992), Des systèmes urbains: pourquoi?, en Le réseau urbain en Belgique dans une perspective historique (1350-1850). Une approche statistique et dynamique, Bruselas, Crédit Communal, pp. 243-248.

Blockmans, Wim (2013), L'unification européenne par les circuits portuaires, en Aguiar, Amélia Andrade; Costa, Adelaide Millán da (coords.), La ville médiévale en débat, Lisboa, Instituto de Estudos Medievais, pp. 133-144.

Blair, John (2000), Small Towns 600-1270, en The Cambridge Urban History. 600-1540, Cambridge, Cambridge University Press, vol. I. pp. 245-270.

Blot, Maria Luisa Pinheiro (2003), Os Portos na origem dos centros urbanos, Lisboa, Instituo portugués de arqueología.

Braudel, Fernand (1976), El Mediterráneo y el mundo mediterráneo en tiempos de Felipe II. Madrid, Fondo de Cultura Económica.

Burkhardt, Mike (2014), Networks as Social Structures in Late Medieval and Early Modern Towns: A Theoretical Approach to Historical Network Analysis, en Caracausi, Andrea; Jeggle, Christof (eds.), Commercial 
networks and European Cities,1400-1800, Londres, Pickering \& Chatto, pp. 13-44.

Casado Alonso, Hilario (2008), Los flujos de información en las redes comerciales castellanas de los siglos XV y XVI, "Investigaciones de Historia Económica" 10, pp. 35-68.

Casado Alonso, Hilario (2010), Genèse et fin des réseaux de commerce castillans dans l'Europe des $X V^{e}$ et $X V I^{e}$ siècles, en Réseaux marchands et réseaux de commerce. Concepts récents, réalités historiques du Moyen Âge au XIX ${ }^{e}$ siècle, Estrasburgo, Presses Universitaires de Strasbourg, pp. 129-149.

Casado Alonso, Hilario (2012), Crecimiento económico, redes de comercio y fiscalidad en Castilla, en Bonachía Hernando, Juan A.; Carvajal de la Vega, David (eds.), Los negocios del hombre: Comercio y rentas en Castilla. Siglos XV y XVI, Valladolid, Castilla, pp. 17-35.

Castro, Américo (1921), Unos aranceles de aduanas del siglo XIII, "Revista de Filología Española" 8, pp. 1-29.

Childs, Wendy. R. (1978), Anglo-Castilian Trade in the Later Middle Ages, Manchester, Manchester University Press.

Childs, Wendy. R. (2003), Commercial relations between the Basque Provinces and England in the Later Middle Ages, c. 1200-c. 1500, "Itsas Memoria. Revista de Estudios Marítimos del País Vasco" 4, pp. 55-64.

Christ, Georg (2014), Beyond the Network, Connectors of Networks: Venetian Agents in Cairo and Venetian News Management, en Conermann, Stephan (ed.), Everything is on the Move. The Mamluk Empire as Node, Bonn, V\&R unipress, pp. 27-59.

Cortes de los antiguos reinos de León y de Castilla. Vol. I, Madrid, Real Academia de la Historia, 1861.

Coulon, Damien; Picard, Christophe; Valérian, Dominique (dirs.) (2007), Espaces et réseaux en Méditerranée. $V I^{e}-X V I^{e}$ siècle, París, Editions Bouchene.

Díez de Salazar, Luis Miguel (1983), El diezmo viejo y seco, o diezmo de la mar de Castilla (s XIII-XVI), San Sebastián, Grupo Dr. Camino de historia de San Sebastián.

Enríquez Fernández, Javier (1988), Colección documental de la villa de Plencia, San Sebastián, Eusko Ikaskutza.

Enríquez Fernández, Javier; Hidalgo de Cisneros Amestoy, Concepción; Martínez Lahidalga, Adela (eds.) (2000), Colección documental del Archivo Histórico de Bilbao (1501-1514), San Sebastián, Eusko Ikaskutza. Falque Rey, Emma (ed.) (1994), Historia Compostelana, Madrid, Akal. 
Ferreira Priegue, Elisa (1988), Galicia en el comercio marítimo medieval, La Coruña, Fundación Pedro Barrié de la Maza.

Ferreira Priegue, Elisa (2002), El fenómeno urbano medieval en Galicia, en Solórzano Telechea, Jesús A.; Arízaga Bolumburu, Beatriz (eds.) El fenómeno urbano medieval entre el Cantábrico y el Duero, Santander, AJHC, pp. 367-420.

Ferreira Priegue, Elisa (2003), Unos mareantes vascos en Barcelona en 1393, "Edades. Revista de Historia" 11, pp. 9.46.

Ferrer i Mallol, Maria Teresa (2003), Los vascos en el Mediterráneo medieval. Los primeros tiempos, "Itsas Memoria. Revista de Estudios Marítimos del País Vasco" 4, pp. 115-128.

Gaibrois Riaño, Mercedes (1922), Historia de Sancho IV de Castilla, Madrid, Editorial Voluntad.

Garay Salazar, Javier; Ojeda San Miguel, Ramón (2003), Notas históricas del noble cabildo de pescadores y mareantes de San Andrés y San Pedro de Castro Urdiales, Bilbao, Beta III Milenio.

García de Cortázar y Ruiz de Aguirre, José Ángel (1982), La sociedad guipuzcoana antes del fuero de San Sebastián, en El fuero de San Sebastián y su época, San Sebastián, Eusko-Ikaskuntza, pp. 89-111.

García de Cortázar, José Ángel; Arízaga Bolumburu, Beatriz; Ríos Rodríguez, María; Val Valdievieso, María Isabel del (1985), Vizcaya en la Edad Media, San Sebastián, Haranburu.

García Oro, José (1987), Galicia en los siglos XIV y XV. Vol. II, Galicia Urbana, Pontevedra, Instituto de Estudios Gallegos Padre Sarmiento.

Gautier-Dalché, Jean (1979) Historia Urbana de León y Castilla (siglos IX al XIII), Madrid, Siglo XXI.

Gilliodts-Van Severen, Louis (1904), Cartulaire de l'ancienne estaple de Bruges: recueil de documents concernant le commerce intérieur et maritime, les relations internationales et l'histoire économique de cette ville, Brujas, L. de Plancke.

González Arce, José D. (2009), La ventaja de llegar primero. Estrategias en la pugna por la supremacía mercantil durante los inicios de los consulados de Burgos y Bilbao (1450-1515), "Miscelánea Medieval Murciana” 33, pp. 92-93.

González Arce, José D. (2015), Los flujos comerciales del puerto de Bilbao con la Europa atlántica (1481-1501), "Cuadernos medievales" 19, pp. 82-110.

González Díez, Emiliano (1984), Colección diplomática del concejo de Burgos, Burgos, Aldecoa.

Guía del peregrino medieval (Codex Calixtinus) (1989), traducción de Millán Bravo Lozano, Sahagún, Centro de Estudios Camino de Santiago. 
Guiard y Larrauri, Teófilo (1972), Historia del Consulado y Casa de Contratación de la villa de Bilbao, Bilbao, La Gran Enciclopedia Vasca.

Hernández, Francisco J. (1993), Las rentas del rey: sociedad y fisco en el reino castellano del siglo XIII. 1: estudio y documentos, Madrid, Fundación Ramón Areces.

Herrero, Victoriano J.; Barrena, Elnae (2006), Archivo Municipal de Deba (1181-1520), San Sebastián, Eusko Ikaskutza.

Hidalgo de Cisneros Amestoy, Concepción; Largacha Rubio, Elena; Lorente Ruigómez, Araceli; Martínez Lahidalga, Adela (1987), Colección documental del Archivo Municipal de Portugalete, San Sebastián, Eusko Ikaskutza.

Igual Luis, David (2013), Red portuaria y control marítimo en el reino de Valencia (siglos XIII-XV), en Les territoires de la Méditerranée. XI ${ }^{e}$ $X V I^{e}$ siècle, Rennes, Presses universitaires de Rennes, pp. 51-71.

Larrañaga Zulueta, Miguel; Tapia Rubio, Izaskun (1993), Colección documental del Archivo Municipal de Hondarribia. (1186-1479), San Sebastián, Eusko Ikaskutza.

Laughton, Jane; Jones, Evan; Dyer, Christopher (2001), The Urban Hierarchy in the Later Middle Ages: A study of the East Midlands, "Urban history" 28/3, pp. 331-357.

Preiser-Kapeller, Johannes (2015), Introduction, en Preiser-Kapeller, Johannes; Daim, Falko (eds.) Harbours and Maritime Networks as Complex Adaptive Systems, Maguncia, Römisch-Germanisches Zentralmuseum, pp. 1-24.

Rivera Medina, Ana María (2016), Navegación, comercio y negocio: los intereses vascos en los puertos flamencos en los siglos VV y XVI, Solórzano Telechea, Jesús Ángel; Arízaga Bolumburu, Beatriz; Bochaca, Michel (eds.), Las sociedades portuarias de la Europa Atlántica en la Edad Media, Logroño, Instituto de Estudios Riojanos, pp. 165-195.

Rodríguez de Diego, José Luis.; Zabalza Duque, Manuel (2012), Documentación de Guipúzcoa en la sección de cámara-pueblos del Archivo General de Simancas, San Sebastián, Eusko Ikaskutza.

Ruiz de la Peña, Juan Ignacio (1981), Las polas asturianas en la Edad Media. Estudio y Diplomatario, Oviedo, Universidad de Oviedo, 1981.

Ruiz de la Peña, Juan Ignacio (1989), El desarrollo urbano de la periferia norteña castellano-leonesa en la Edad Media (siglos XII-XIV), "Anuario de Estudios Medievales" 19, pp. 169-186.

Ruiz de la Peña, Juan Ignacio (1997), La función comercial de las villas nuevas del norte de España en la Edad Media (1150-1300 ca.), en Viajes y viajeros en la España medieval, Madrid, Centro de Estudios del Románico,pp. 177-192. 
Rymer, Thomas (1740), Foedera, conventiones, literae et cuiuscunque generis acta publica inter reges Anglie, vol. VI, Londres.

Scott, Tom; Scribner, Bob (1996), Urban networks, en Scribner, Bob (ed.), Germany: a new social and economic History, Londres, Hodder Education Publishers, vol. I, pp. 113-143.

Sainz Díaz, Valentín (1986), Notas históricas sobre la villa de San Vicente de la Barquera, Santander, Librería Estvdio.

Sanz Fuentes, María Josefa; Álvarez Castrillón, José; Calleja Puerta, Miguel (2013), Colección diplomática del concejo de Avilés en la Edad Media (1155-1498), Avilés, Ayuntamiento de Avilés.

Sebastián Moreno, Javier (2017), Las regiones de abastecimiento de la ciudad de Burgos en el siglo XV y el papel de la nobleza en el suministro urbano, Jara Fuente, José Antonio (ed.), Discurso político y relaciones de poder. Ciudad, nobleza y monarquía en la Baja Edad Media, Madrid, Dykinson.

Solano Fernández-Sordo, Álvaro (2016), De Maliayo a Villaviciosa. Un territorio de la Marina centro-oriental de Asturias en la Edad Media, Oviedo, Fundación José Cardín Fernández.

Solórzano Telechea, Jesús Ángel (1995), Colección diplomática del Archivo Municipal de Santander (1295-1504), Santander, Fundación Marcelino Botín.

Solórzano Telechea, Jesús Ángel; Fernández González, Lorena (1996) Conflictos jurisdiccionales entre la villa de Santander y el marquesado de Santillana en el siglo XV, Santander, Fundación Marcelino Botín.

Solórzano Telechea, Jesús Ángel (1998), Patrimonio documental de Santander en los archivos de Cantabria. Documentación medieval, Santander, Gobierno de Cantabria.

Solórzano Telechea, Jesús Ángel; Arízaga Bolumburu, Beatriz (eds.) (2002) El fenómeno urbano medieval entre el Cantábrico y el Duero, Santander, AJHC.

Solórzano Telechea, Jesús Ángel (2007-2008), Los puertos del Rey: síntesis interpretativa del fenómeno urbano en el Norte de España durante los siglos XII y XIII, "Temas Medievales" 15-16, pp. 257-273.

Solórzano Telechea, Jesús Ángel (2009a), Villas y redes portuarias en la fachada atlántica del norte peninsular en la Edad Media, en Val Valdivieso, María Isabel del; Martínez, Pasqual (dirs.), Castilla y el mundo feudal. Homenaje a Julio Valdeón Baruque, Valladolid, Junta de Castilla y León, Consejería de Cultura y Turismo - Universidad de Valladolid, vol. I, pp. 485-502. 
Solórzano Telechea, Jesús Ángel (2009b), Medieval Seaports of the Atlantic Coast of Spain, "International Journal of Maritime History" 21, pp. 81-100.

Solórzano Telechea, Jesús Ángel (2010), Las Nereidas del Norte: puertos $e$ identidad urbana en la fachada cantábrica entre los siglos XII$X V$, "Anales de la Universidad de Alicante. Historia Medieval" 16, pp. 19-41.

Solórzano Telechea, Jesús Ángel (2013), La primera internacionalización de la economía española en la baja Edad Media: de la Hermandad de la Marina del Cantábrico a la Nación de la Costa de España, en Solórzano Telechea, Jesús Ángel; Viana, Mário (eds.), Economia e instituiçoes na Idade Média: novas abordagens, Ponta Delgada, Centro de Estudios Gaspar Frutuoso.

Solórzano Telechea, Jesús Ángel (2015), La Nación de Vizcaya y de la Marina Costa Marina de España: la colonia de mercaderes, marineros y transportistas del cantábrico en la ciudad de Brujas en la Edad Media, en Solórzano Telechea, Jesús Ángel; Arízaga Bolumburu, Beatriz; Sicking, Louis (eds.), Diplomacia y comercio en la Europa atlántica medieval, Logroño, Instituto de Estudios Riojanos, pp. 221-244.

Suárez Fernández, Luís (1950), Intervención de Castilla en la Guerra de los Cien Años, Valladolid, Industrias Gráficas ESPE.

Suárez Fernández, Luís (1959), Navegación y comercio en el golfo de Vizcaya: Un estudio sobre la política marinera de la casa de Trastámara, Madrid, Escuela de Estudios Medievales.

Suárez Fernández, Luís (1966), Política internacional de Isabel La Católica. Estudio y documentos. Tomo II (1482-1488), Valladolid, Universidad de Valladolid.

Tranchant, Mathias (2003), Le commerce maritime de La Rochelle à la fin du Moyen Âge. Rennes, Presses universitaires de Rennes.

Vandewalle, André (2002), Les nations étrangeres à Bruges, en Les marchands de la Hanse et la banque des Médicis. Bruges, marché d'échanges culturels en Europe, Oostkamp, Stichting Kunstboek.

Vítores Casado, Imanol; Goicolea Julián, Javier; Angulo Morales, Alberto; Aragón Ruano, Álvaro (eds.) (2015), Hacienda, fiscalidad y agentes económicos en la Cornisa Cantábrica y su entorno (1450-1550), Vitoria, Universidad del País Vasco.

Fecha de recepción del artículo: octubre 2017

Fecha de aceptación y versión final: mayo 2018 